\title{
Global Healthcare Workers Migration: A Human Resource Management Concern
}

\author{
James Ducey and Satesh Bidaisee* \\ Associate Professor of Public Health and Preventive Medicine, St. George's University, West Indies
}

Submission: August 03, 2018; Published: November 19, 2018

"Corresponding author: Satesh Bidaisee, Associate Professor of Public Health and Preventive Medicine, St. George's University, West Indies.

\begin{abstract}
The World Health Organization estimates a deficit of approximately 2.4 million physicians, nurses, and midwives along with a need for an additional 2 million pharmacists and paramedical professionals. Compounding this crisis for the most vulnerable communities is the phenomenon healthcare worker migration. Both developed and developing nations are struggling to mitigate the immense challenges resulting from the existing shortage combined with increasing demands and diminishing supplies of healthcare providers. WHO established a Global Code of Practice with the aim of addressing the growing healthcare worker crisis. United Nations General Assembly passed a resolution calling on the international community to work together towards the creation of 40 million healthcare and social workers with particular focus on the expected 18-million-person deficit in healthcare workers by 2030. The WHO's Global Code of Practice on the International Recruitment of Health Personnel has provided clear benefits in mitigating this growing problem most evident with the creation of 117 national authorities and being used to establish 65 bilateral agreements with respect to health worker development and migration. The healthcare workforce shortage is an ongoing crisis with global ramifications effecting developed and developing nations alike.
\end{abstract}

Keywords: World Health Organization; Healthcare; Shortage; Phenomenon and Migration

\section{Introduction}

Shortages within the healthcare workforce represent a growing problem for the Americas. This problem is but a portion of a global crisis. The World Health Organization estimates a deficit of approximately 2.4 million physicians, nurses, and midwives along with a need for an additional 2 million pharmacists and paramedical professionals [1]. Both developed and developing nations are struggling to mitigate the immense challenges resulting from the existing shortage combined with increasing demands and diminishing supplies of healthcare providers [2]. Overall issues are further complicated in that healthcare workers are most sparse in regions in which they are most desperately needed, particularly impoverished, developing nations [2]

Compounding this crisis for the most vulnerable communities is the phenomenon healthcare worker migration. A prime example of this sub-Saharan Africa, which carries $24 \%$ of the world's disease burden, while only have $3 \%$ of the global healthcare workforce to combat it, as well as merely $1 \%$ of global financial resources to fund any and all health initiatives [1]. The reasons for this migration are multifaceted and in recent history has become increasingly complex $[3,4]$. Some factors which contribute to health worker migration include: active recruitment of healthcare workers to wealthy nations at the detriment to their respective home countries or countries in which they were trained, insufficient health systems, poor working conditions, lack of recognition, overwork, low wages in these developing nations [3]. All of these factors contribute to the increasingly low health worker numbers in the most vulnerable countries [3].
In response to this ongoing crisis, the WHO established the Global Code of Practice on the International Recruitment of Health Personnel in 2010. After detailing the aims of this WHO initiative and summarizing its current progress, this review will present both the successes and obstacles to this initiative; then focusing particularly on how implementation has progressed in the Americas. Concluding with an evaluation as to which targeted initiative hold promise in mitigating the disparity in the capabilities with regard to providing healthcare when comparing developed and developing nations.

\section{Global Code of Practice on the International Recruit- ment of Health Personnel}

In 2010, the WHO established a Global Code of Practice with the aim of addressing the growing healthcare worker crisis. The objectives of this code are as follows: to establish and promote voluntary principles and practices for the ethical international recruitment of health personnel, with respect to both source and destination; to create a reference for nations while establishing or improving the infrastructures necessary for international recruitment of health personnel; to provide guidance where appropriate with regards to the formulation and implementation of bilateral and/or multilateral; to facilitate and promote international discussion and advance cooperation related to the ethical international recruitment of health personnel as part of strengthening health systems, with a particular focus on the situation of developing countries [5]. These objectives aim to mitigate the growing health personnel crisis across the globe. The 
Global Code of Practice outlines several important methods for addressing this growing concern. Overall, the aim is to improve the healthcare workforce globally. Methods for doing so include increasing healthcare education, training, efficiency. The ultimate goal with regards to training and education being to have a system of generate a healthcare workforce which is self-sustaining for each individual nation, as sourcing healthcare workers from other nations inherently places strain on the healthcare system of the source country. Another important aspect is the collection of pertinent data and the establishment oversight bodies to monitor and make recommendations from information collected, and to share this information with international agencies in order to aid with overcoming issues from a more global mindset [5]. This data gathering, and international cooperation is especially important for the most vulnerable communities where resources and healthcare work-forces are under the greatest strain [5].

Finally, the Global Code of Practice established in 2010 sought to develop a means of regulating healthcare worker migration in a manner as to aid the most vulnerable nations. It is important to understand that this regulation must be undertaken with respect to any nation's obligations to its own citizenry as well as with respect to the liberties any particular healthcare worker [5]. Essentially, the goal with respect to healthcare worker migration is to permit the free migration of healthcare workers while encouraging the bolstering of vulnerable healthcare systems and allowing decreasing the limitations of free mobility of health professionals.

Current Progress with Implementation of the Global Code of Practice. Since the establishment of the Global Code of Practice, international consensus is that it has had a positive effect on addressing the health personnel crisis. A recent meeting among high profile entities working with the World Health Organization highlighted some of these factors focusing on international health worker migration [6]. The meeting affirmed that the Global Code of Practice is working to mitigate the health personnel crisis, most effectively by elucidating various problems within the current global state of health worker migration, allowing for discussion to methods of amelioration [6].

Some countries have successfully implemented strategies to drastically increase the production of new health workers. The successes can be used to develop policies in other nations as well as a possible resource of health workers for nations without the capacity for such production [6]. Other policy measures are being implemented at both the national level and with bilateral agreements to create environments with mutually beneficial health worker migration, implementation and improvements to health worker monitoring and management information systems, recruitment health workers to rural communities [6]. The potential of appropriate utilization and integration of refugee health workers and potential training of refugees as health workers.

Challenges to implementation include: differences in populations, capacity to educate new health workers, capability to train health workers with new technologies, impediments to health worker skill recognition, lack of prioritization with regard to specializing training and employment of health worker at the national level, as well as predatory practices in recruiting health workers [6]. Other factors outside a health worker migration such as increasing burden of chronic conditions, anti-globalization sentiments, and growing refugee populations [6].

Presented during the meeting was evidence demonstrating the necessity for a more refined and evidence-based approach to addressing the increasing scope and complexity of international health worker migration [6]. This approach is key towards the success of Global Code of Practice being successful. The meeting closed with calling for a third round of National Reporting to the World Health Organization regarding health personnel and health worker migration [6].

With respect to the challenges still clearly evident, the successes of World Health Organization promoted practices is deserving of recognition. Since the adoption of the Global Code of Practice, the world has seen the creation of 117 national authorities dedicated to its implementation as well as the Code being used to establish 65 bilateral agreements with respect to health worker development and migration [7]. The recommendations from information gathered regarding health personnel has also resulted in recognition from the United Nations. In 2016, the United Nations General Assembly passed a resolution calling on the international community to work together towards the creation of 40 million healthcare and social workers with particular focus on the expected 18-million-person deficit in healthcare workers by 2030 [8].

\section{National Reporting on Status of Health Personnel Workforce}

As outlined in the Global Code of Practice, information gathering, and national reporting are integral to implementing, monitoring, and improving efforts to address the health worker shortage. Since the inception of the Code, there have been two rounds of National Reporting. Of the 194-member states 74 submitted National Reports to the World Health Organization in 2016 [7]. This represents a 32\% increase in participating nations from the first round of reporting [7]. While the Pan American Health Organization demonstrated a drastic increase between the first and second round of reporting, from 4 to 9 members submitting National reports in 2013 and 2016 respectively; this still represents only $26 \%$ of the 35 members [7]. The importance of data gathering cannot be underestimated without inhibiting global and regional efforts to increase the health workforce.

\section{Health Personnel Workforce in the Americas}

Back in 2005, experts from around the Caribbean and Latin America gather for a conference to discuss and coordinate measures to enact policies of managed migration [9]. An important reason for these efforts is to mitigate the brain drain of professionals form the regions across multiple industries and sectors [9]. Of particular importance was the retention health professionals [9]. 
The Pan American Health Organization has overseen successes in the implementation of the Global Code of Practice. This is exemplified by the increases in physicians per capita as depicted in Figure 1. Of all the Pan American Health Organization countries which submitted data for multiple years, the vast majority saw improvements. This indicates that monitoring these statistics provides information which can positively inform policy. It also shows which countries are not implement effective policies, which can be seen as a marker for further changes, possibly with a different approach.

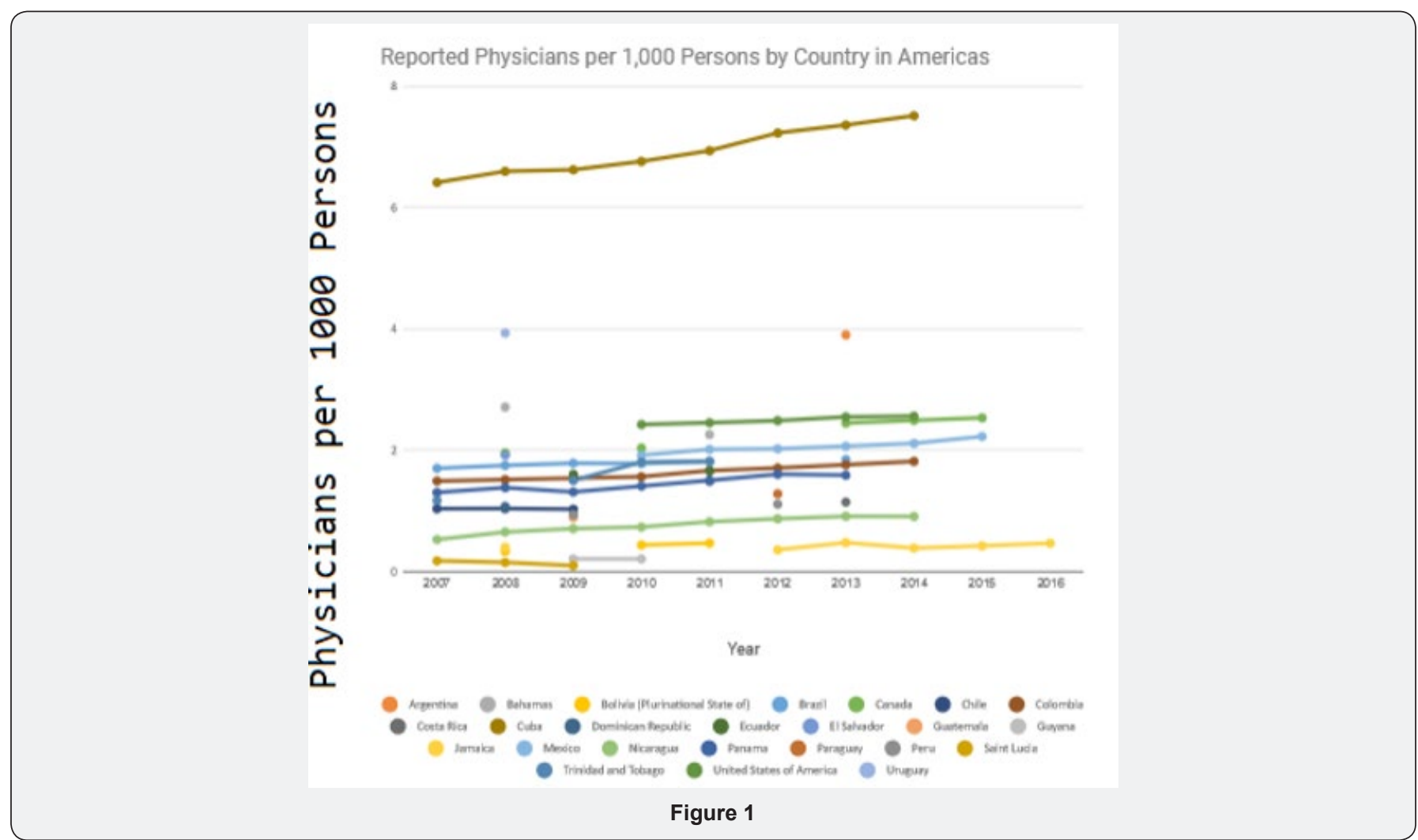

However, the Americas have faced a number of difficulties particularly amongst the poorer nations. To establish a holistic picture of the current state of health personnel shortages and health worker migration in the Americas analyses from threemember states: the United States of America, Canada, and El Salvador will serve as examples. These three nations represent both developed and developing countries, as well as presenting health worker shortages in both socialized and privatized health systems.

\section{United states}

Prior to the creation of the World Health Organization Code of Practice, the Alliance for International Ethical Recruitment Practices was developed in the United States [10]. The Alliance Code in light of drastic increases in the number of firms actively recruiting foreign nurses. This dramatic and unregulated market created an environment which enable unfair and subversive recruitment practices which disadvantaged incoming healthcare worker migrants coming to the United States [11]. The purpose of the implementing the Alliance Code was to establish minimum standards for employers and recruiters to ensure transparent, reasonable, and ethical practices for contracting international workers in addition to setting goals of best practices respecting health worker rights to labor autonomy while mitigating the detriments encumbered by source countries' healthcare systems
[10]. While the Alliance Code is distinct from the World Health Organization Code of Practice, both share the same aspirations and goals [11]. The World Health Organization Code of Practice is a broad set of guidelines for national and international agencies, while the Alliance Code represents a more narrowed and detailed set of guidelines for a particular aspect of this issue, namely healthcare worker recruitment practices. Since the inception of the Alliance Code the following strategies have been identified as crucial for its ultimate success: a multi-stakeholder approach, realizing the potential impacts of variations in immigration policy, challenges with enforcing compliance with a voluntary set of guidelines, generating understanding of the importance of ethical practice at the level of individual recruitment employees, standardizing credential assessment and certification [11].

\section{Canada}

In contrast, Canada has a single-payer healthcare system. As such, the government has a much greater deal of control with regard to ethical recruitment practices. However, governmentfunded health systems face their own challenges regarding health worker shortages. Since the mid-2000's the number of immigrating health professionals has been increasing in Canada, particularly physicians and nurses [2]. International health professionals have been vital to Canadian physician resource planning [12]. As a matter of policy, efforts to maintain these trends in order 
to alleviate the healthcare worker shortage persisted in spite of economic hardship during the global recession, and efforts to improve integration of international health professional are underway [2]. The major threat to continued addressing of the labor shortage in Canada is financial constraints and political climate is trending toward addressing government debts and deficits [2]. The significant and increasing numbers of health migrants to Canada suggests that the nation may be exacerbating shortages in less developed source nations, however evidence shows there is also substantial increases in health professionals trained in Canada preparing to emigrant elsewhere represents a mitigating factor in Canadian overall health worker policy [2]. While compliance with the World Health Organizations' Code of Practice is a topic in healthcare policy discussions in Canada, current political climate indicates that efforts to address the health professional workforce within Canada, especially in underserved communities seem to be taking priority [2]. While discussions are also underway in Canada to promote the development of education system to create a self-sustaining healthcare environment, the Canadian Medical Association regards international professionals a significant component of Canadian health workforce planning $[13,14]$.

\section{El salvador}

Moving from the developed countries to developing nations, El Salvador has again its own unique challenges to combatting the healthcare worker shortages. Researchers discuss the legal implications of the World Health Organization Code of Practice and how coordination between national agencies is needed to implement the guidelines [2]. Overall, the understanding with regards to El Salvador is that the Code of Practice is too broad in its scope and lacks concrete definitions which would be necessary for it to be used as a source of regulation. Recommendations propone for the Code to be technically assessed by the Ministry of Health, and for those assessments to be given to lawmakers to enact legislation as would be appropriate to best serve the people [2]. The key difference to be noted is that while El Salvador intends to use government intervention to enact these changes as in Canada, limited resources called for careful assessment prior to implementation [2]. Since El Salvador is a common source country for health workers migrating to more developed countries like Canada and the United States, there is also an emphasis on the components of the Code of Practice relating to retaining health workers with possible policy changes both encouraging health professionals to stay or creating barriers to their emigration, while maintaining respect for individual autonomy [2].

\section{Conclusion}

The healthcare workforce shortage is an ongoing crisis with global ramifications effecting developed and developing nations alike. The World Health Organization's Global Code of Practice on the International Recruitment of Health Personnel has provided clear benefits in mitigating this growing problem most evident with the creation of 117 national authorities and being used to establish 65 bilateral agreements with respect to health worker development and migration [7]. Additionally, in 2016, the United Nations General Assembly passed a resolution calling for the creation of 40 million healthcare and social workers by 2030 [8]. It has been made clear from evidence around the world and shown here across the Americas that addressing the health professional shortage is a complex and multi-faceted endeavor. The more information we gather the better able we are to identify which particular problems are arising in particular regions. Many of the lessons learned thus far can be used to influence further policy developments at the regional, national, international level. One obvious aspect in which the Americas stand to directly benefit is by increasing participation in the next round of National reporting to the World Health Organization. Again, the Pan American Health Organization demonstrated a drastic increase between the first and second round of reporting, from 4 to 9 members submitting National reports in 2013 and 2016 respectively; this still represents only $26 \%$ of the 35 members [7]. Increasing the available data will serve both to benefit members of the Pan American Health Organization as well as nations across globe.

\section{References}

1. WHO (2006) Health workers: a global profile. In: The World Health Report 2006-Working together for health. Geneva: World Health Organization.

2. WHO (2013) WHO policy dialogue on international health workforce mobility and recruitment challenge. In: Technical report Copenhagen. The WHO Regional Office for Europe.

3. Nair M, Webster P (2013) Health professionals' migration in emerging market economies: patterns, causes and possible solutions. J Public Health 35(1): 157-163.

4. Taylor AL, Dhillon IS (2011) The WHO Global Code of Practice on the International Recruitment of Health Personnel: The Evolution of Global Health Diplomacy. Global Health Governance 1(1).

5. WHO Global Code of Practice for International Recruitment of Health Personnel.

6. High Level Dialogue.

7. SDG3. C .1 Health Worker Density and Distribution Health Worker Labour Mobility

8. 2016 Un General Assembly Resolution A/RES/71/159.

9. Global Health Observatory Statistics.

10. 2008 Alliance for Ethical International Recruitment Practices. Voluntary code of ethical conduct for the recruitment of foreign educated health professionals to the United States. Washington, DC, USA.

11. Code for ethical international recruitment practices: the CGFNS alliance case study.

12. ACHDHR (2009) How many are enough? Redefining self-sufficiency for the health workforce, A Discussion Paper. Canadian Federal/ Provincial/Territorial, Advisory Committee on Health Delivery and Human Resources, Ottawa, ON: Health Canada.

13. CMA, CCCPR (2008) International Medical Graduates in Canada, Ottawa, ON: Canadian Medical Association and Canadian Collaborative Centre for Physician Resources.

14. Expert Group Meeting on International Migration and Development in Latin America and the Caribbean. 
(c) (i) This work is licensed under Creative cc) Commons Attribution 4.0 License

\section{Your next submission with Juniper Publishers} will reach you the below assets

- Quality Editorial service

- Swift Peer Review

- Reprints availability

- E-prints Service

- Manuscript Podcast for convenient understanding

- Global attainment for your research

- Manuscript accessibility in different formats ( Pdf, E-pub, Full Text, Audio)

- Unceasing customer service

Track the below URL for one-step submission https://juniperpublishers.com/online-submission.php 